Adam W. Ferguson*, Houssein R. Roble and Molly M. McDonough

\title{
Noteworthy record of the Ethiopian genet, Genetta abyssinica, (Carnivora, Viverridae) from Djibouti informs its phylogenetic position within Genetta
}

https://doi.org/10.1515/mammalia-2017-0081

Received June 23, 2017; accepted May 17, 2018; previously published online July 10, 2018

Abstract: The molecular phylogeny of extant genets (Carnivora, Viverridae, Genetta) was generated using all species with the exception of the Ethiopian genet Genetta abyssinica. Herein, we provide the first molecular phylogenetic assessment of $G$. abyssinica using molecular sequence data from multiple mitochondrial genes generated from a recent record of this species from the Forêt du Day (the Day Forest) in Djibouti. This record represents the first verified museum specimen of $G$. abyssinica collected in over 60 years and the first specimen with a specific locality for the country of Djibouti. Multiple phylogenetic analyses revealed conflicting results as to the exact relationship of G. abyssinica to other Genetta species, providing statistical support for a sister relationship to all other extant genets for only a subset of mitochondrial analyses. Despite the inclusion of this species for the first time, phylogenetic relationships among Genetta species remain unclear, with limited nodal support for many species. In addition to providing an alternative hypothesis of the phylogenetic relationships among extant genets, this recent record provides the first complete skeleton of this species to our knowledge and helps to shed light on the distribution and habitat use of this understudied African small carnivore.

Keywords: distribution; Djibouti; Genetta abyssinica; habitat; phylogeny.

\footnotetext{
*Corresponding author: Adam W. Ferguson, Field Museum of Natural History, 1400 South Lake Shore Drive, Chicago, IL 60605, USA, e-mail:aferguson@fieldmuseum.org

Houssein R. Roble: Environment and Sustainable Development Ministry of Housing, Urban Planning and Environment, BP 2091, Republic of Djibouti

Molly M. McDonough: National Museum of Natural History, Smithsonian Institution, 10th St. and Constitution Ave. NW, Washington, DC 20560, USA; and Center for Conservation Genomics, Smithsonian Conservation Biology Institute, National Zoological Park, 3001 Connecticut Ave NW, Washington, DC 20008, USA
}

\section{Introduction}

The Ethiopian or Abyssinian genet (Genetta abyssinica, Rüppell 1836) is a diminutive species of genet (Carnivora, Viverridae) restricted to the Horn of Africa (Gaubert 2013). Originally thought to occur only in arid habitats, subsequent investigations indicated that G. abyssinica actually inhabits a broad altitudinal and ecological range (Yalden et al. 1996). Based solely upon 18 museum specimens and a single ecological study from the highlands of Ethiopia (Diaz Behrens and Van Rompaey 2002), G. abyssinica is thought to occur from coastal plains and dry lowlands to high plateaus in Eritrea, Djibouti, Ethiopia, Somalia and Sudan (Gaubert 2013). Predictions based on ecological niche models generated using 12 georeferenceable museum vouchers indicated that open/sparse grasslands in Eritrea and surrounding countries and deciduous-shrubland and montane forest in western Ethiopia composed the most suitable range for G. abyssinica (Papeş and Gaubert 2007). Papeş and Gaubert (2007) also found that such suitable areas for G. abyssinica were often isolated by unsuitable areas dominated by croplands, where a majority of historical records are now located. Even with this understanding of its broad niche, newly gathered information continues to shed light on the ecology of this poorly studied species, e.g. the first discovery of G. abyssinica in forested habitats of the Abune Yosef Massif, Ethiopia (Diaz Behrens and Van Rompaey 2002). Thus, continued studies of $G$. abyssinica across its range are important for elucidating its ecological requirements, conservation status and distributional limits.

Beyond the limited understanding of the ecology of Genetta abyssinica, its phylogenetic relationship to other genets also remains obscure. Traditionally included in the subgenus Pseudogenetta Dekeyser, 1949 together with the similar-sized Haussa genet Genetta thierryi Matschie, 1902 (Crawford-Cabral 1981), G. abyssinica is considered a primitive genet based on shared characteristics (e.g. hairless central depression of the forefoot) with African linsangs or oyans of the genus Poiana Gray, 1864 (Crawford-Cabral 1981). Although the validity of Pseudogenetta has been brought into question, morphological analyses have 
confirmed the monophyletic sister-relationship between G. abyssinica and G. thierryi (Gaubert et al. 2002). Molecular studies aimed at addressing the debated systematics and phylogenetics of the genus Genetta Cuvier, 1816 have included all living species of morphologically recognized genets with the exception of G. abyssinica (Gaubert et al. 2004, Gaubert and Begg 2007). Thus, although Gaubert et al. (2004) predict a sister relationship between G. abyssinica and G. thierryi, no molecular data, neither DNA sequence nor karyological, exist for evaluating this relationship (Gaubert et al. 2004, Gaubert and Begg 2007). Given the potential sister relationship of G. thierryi and G. abyssinica and their hypothesized primitive status in relation to extant genets, including the basal rain forest lineage, elucidating the phylogenetic position of G. abyssinica is crucial for understanding evolutionary transitions from forest dependent to savanna adapted Genetta species or vice versa (Gaubert et al. 2004). Although historical museum specimens can provide alternatives to modern tissue samples, work on genets indicates that obtaining fresh samples from morphologically recognizable/vouchered specimens is critical for accurately assessing phylogenies of these closely related species (Gaubert and Begg 2007).

Herein, we report the first record of an Ethiopian genet, Genetta abyssinica from Djibouti with verifiable locality data in over 60 years together with a first assessment of its position within the Genetta molecular phylogeny based on mitochondrial DNA sequences. Based on previous assessments using morphological cladistics, we hypothesize that G. abyssinica will form a monophyletic clade with Genetta thierryi which will be sister to all other extant Genetta. This recently collected specimen of G. abyssinica provides important information regarding the species habitat requirements, confirms its modern presence in the country of Djibouti, and facilitates the first molecular sequence data for assessing its phylogenetic relationship to other living genets.

\section{Materials and methods}

\section{Sampling}

In February 2016, a joint expedition between the Global Genome Initiative (GGI) at the Smithsonian Institution's National Museum of Natural History (NMNH) and the US Navy's Natural Resources Program was undertaken to characterize biodiversity of the US military base at Camp Lemonnier, Djibouti, Africa. During this time, a brief visit to the Forêt du Day (the Day Forest) was arranged through the Environment and Sustainable Development Ministry of Housing, Urban Planning and Environment. On 18 February 2016, a single adult male (testes $=12 \times 8 \mathrm{~mm}$, scrotal) specimen of Genetta abyssinica was captured in a Tomahawk live trap [Model 205, (Hazelhurst, WI, USA) $66 \times 23 \times 23 \mathrm{~cm}$ ] baited with raw chicken and raw beef. The trap was set in the Forêt du Day along a dry, rocky drainage flowing southwest from the Garab Plateau into the Ourano Wadi $\left(11^{\circ} 46^{\prime} 6.35^{\prime \prime} \mathrm{N}, 42^{\circ} 39^{\prime} 6.15^{\prime \prime} \mathrm{E}, 1420 \mathrm{~m}\right.$ a.s.l, Figures 1 and 2). Additional mammals observed in the vicinity of the trap included: Hamadryas baboon Papio hamadryas (Linnaeus, 1758), rock hyrax Procavia capensis (Pallas, 1766), white-tailed mongoose Ichneumia albicauda (G. [Baron] Cuvier, 1829), domestic cat (Felis catus Linnaeus, 1758), striped hyaena Hyaena hyaena (Linnaeus, 1758), pygmy gerbil (Gerbillus Desmarest, 1804), and Cairo spiny mouse Acomys cf. cahirinus (Desmarest, 1819). The Forêt du Day, Republic of Djibouti, or Day National Forest, consists of dry tropical Afromontane mixed woodland dominated by the African pencil juniper Juniperus procera and is best known for maintaining the world's largest population of the critically endangered Djiboutian Francolin, Francolinus ochropectus (Fisher et al. 2009). Other dominant plants in the Forêt du Day include Buxus hildebrantii, Olea africana and Tarchonanthus camphoratus. Once captured, the animal was euthanized following ethical guidelines provided by the American Society of Mammalogists (Sikes and Animal Care and Use Committee of the American Society of Mammalogists 2016) and the NMNH Institutional Animal Care and Use Committee (IACUC Permit \#2014-11). The skin, skull and post-cranial skeleton were prepared and deposited in the Smithsonian Institution's National Museum of Natural History [The U.S. National Museum (USNM) 602624] together with a whole blood sample in an RNA stabilization buffer and ectoparasites (fleas and ticks in 95\% ethanol). Tissue samples, including muscle in lysis buffer (USNM Biorepository numbers AE7VV87, AE7VV88, AE7VV89) and liver in 95\% ethanol (AD5JH94) were collected in the field and transferred to long-term liquid nitrogen storage facilities at the NMNH Biorepository (http://naturalhistory.si.edu/rc/ biorepository/).

\section{DNA sequencing}

A single tissue sample stored in buffer was extracted using DNeasy blood and tissue kit (Qiagen, Valencia, CA, USA) following manufacturer's protocols. The entire mitochondrial genome was amplified using two sets of universal primers: 1) tRNA Leuc1 and $16 S$ rRNA1, and 2) tRNA Leuc2 and $16 S$ rRNA2 (Sasaki et al. 2005). The amplification reactions included 50 ng of genomic DNA, $12.5 \mu \mathrm{l}$ of KAPA HiFi 


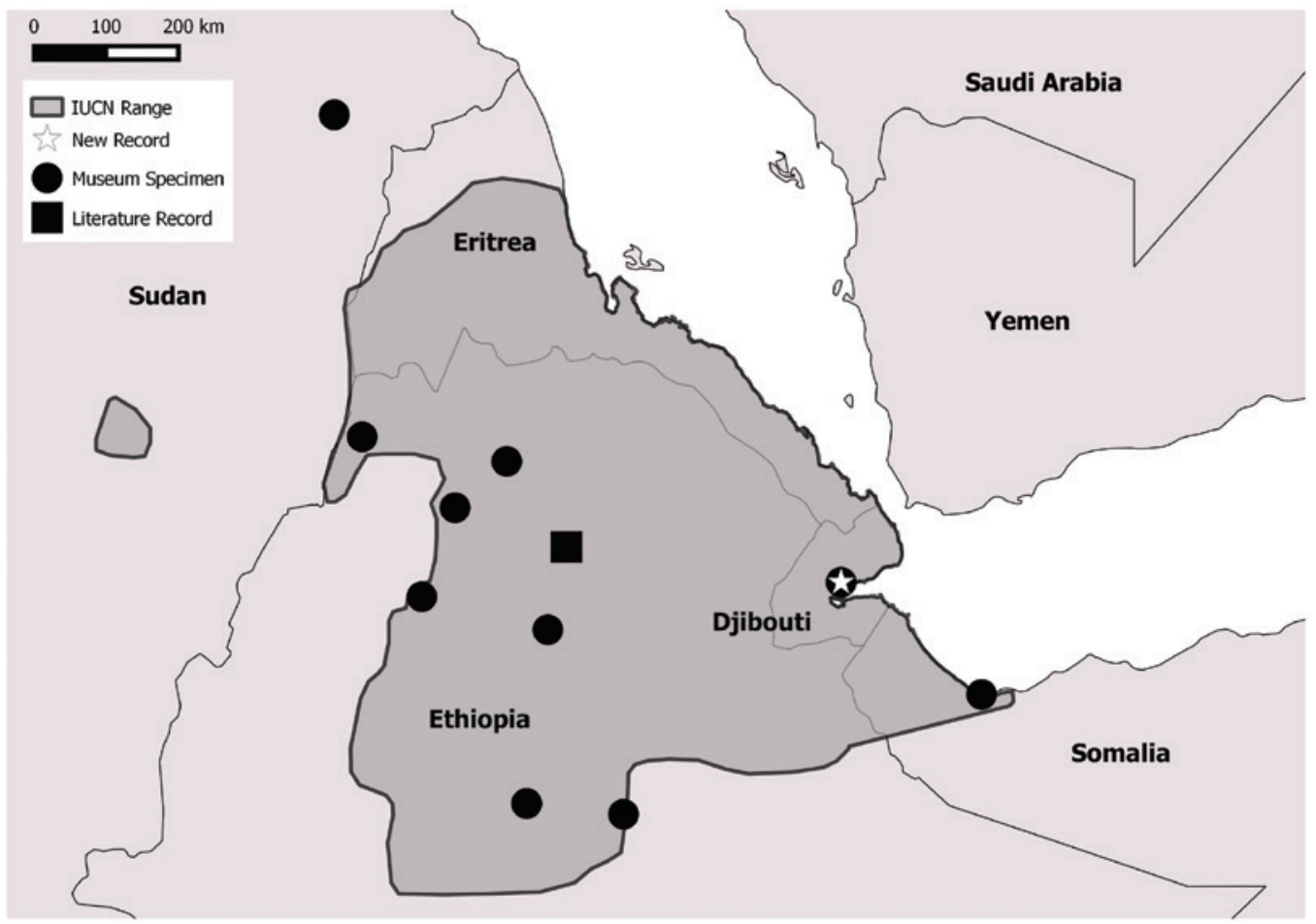

Figure 1: Distribution of Genetta abyssinica based on IUCN with new (USNM 602624) and historical records referenced in this study. All geographic coordinates for specimens depicted in this map with the exception of the new record were taken verbatim from Papeş and Gaubert (2007).

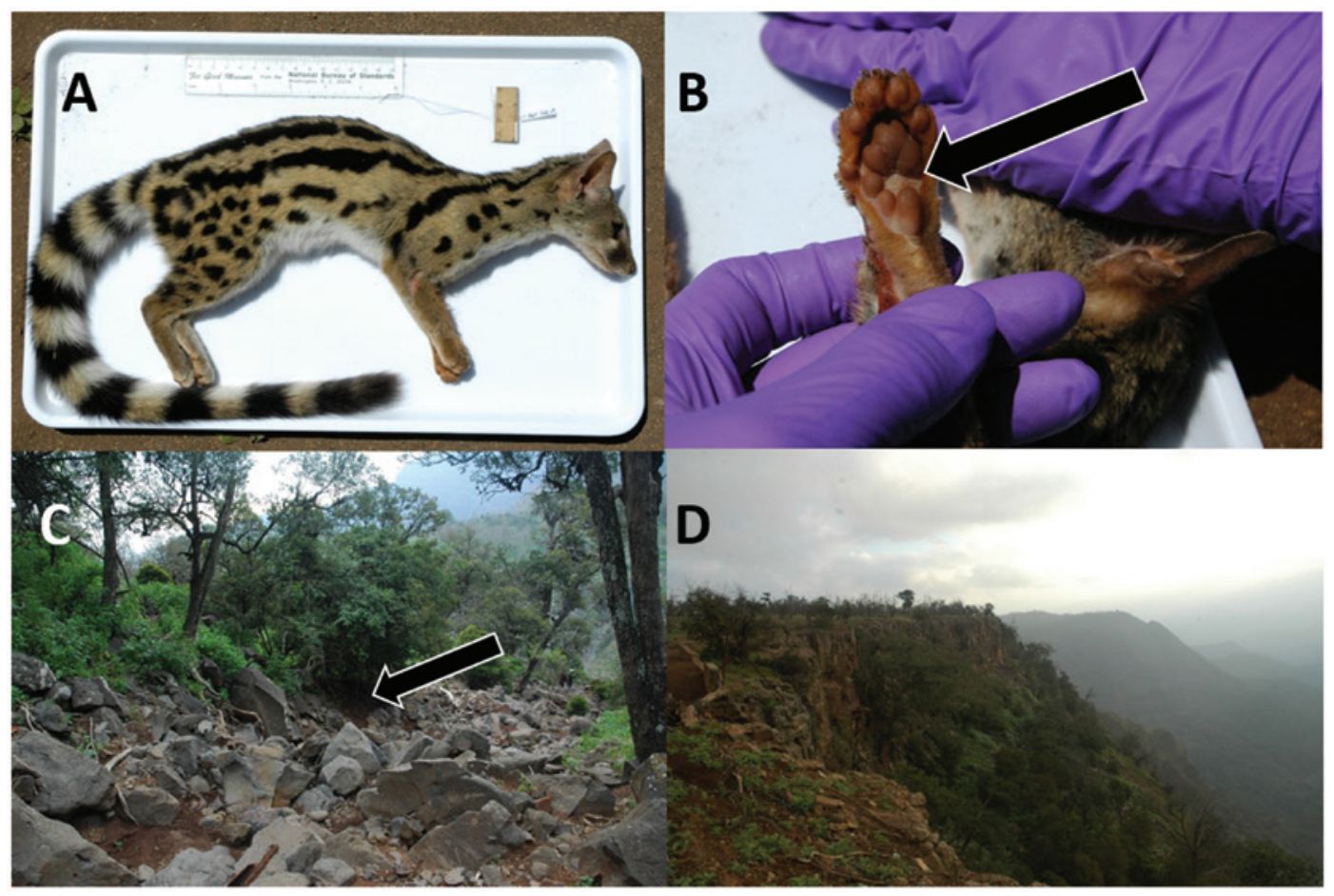

Figure 2: Specimen and habitat photographs of the Ethiopian genet (Genetta abyssinica) collected in Djibouti that was used to test its molecular phylogenetic position for the first time.

Adult male Genetta abyssinica (USNM 602624) collected in the Forêt du Day, Tadjourah Province, Djibouti on 18 February 2016 (A).

Photograph of the left front foot of Genetta abyssinica (USNM 602624) depicting the hairless central depression (black arrow) that is characteristic of this species (B). Habitat immediately surrounding trap location (black arrow) where USNM 602624 was captured (C). Photograph from the top of the plateau where USNM 602624 was collected (D). 
Hotstart ReadyMix (KAPA Biosystems, Boston, MA, USA), $0.3 \mu \mathrm{M}$ of each primer, and polymerase chain reaction (PCR)-grade water for a final volume of $25 \mu \mathrm{l}$. Reactions were denatured at $98^{\circ} \mathrm{C}$ for $5 \mathrm{~min}$ followed by 35 cycles of: $95^{\circ} \mathrm{C}$ for $20 \mathrm{~s}$ and $68^{\circ} \mathrm{C}$ for $10 \mathrm{~min}$; followed by a final extension at $72^{\circ} \mathrm{C}$ for $5 \mathrm{~min}$. PCR products were visualized for correct size fragments using $3 \mu \mathrm{l}$ of product in a 1.5\% agarose gel with GelRed (Biotium, Hayward, CA, USA) and NEB 1 kb ladder (New England Biolabs, Beverly, MA, USA). The remaining PCR products were cleaned with 1.8X SeraPure magnetic beads (Rohland and Reich 2012). The PCR fragments were quantified using Qubit 2.0 (Life Technologies, Thermo Fisher Scientific, Waltham, MA, USA) fluorometric assay and were pooled at an equimolar ratio. The library construction was performed using a Nextera XT DNA Library Kit (Illumina, San Diego, CA, USA) following manufacturer's protocols. The final products were cleaned using 1.8X SeraPure magnetic beads and resuspended in $52.5 \mu \mathrm{l}$ of the Nextera resuspension buffer. The fragment sizes were validated using an Agilent High Sensitivity DNA Kit (Agilent Technologies, Santa Clara, CA, USA). The final library was quantified using Qubit and the concentration in nanomole was calculated following the Illumina protocol. The library was diluted to $4 \mathrm{~nm}$ using $10 \mathrm{~mm}$ Tris pH 8.5 and sequences were generated on a single MiSeq run using a 300 cycle v2 PE Kit (Illumina).

\section{Phylogenetic analysis}

Paired-end reads were trimmed of adapter sequences using Cutadapt v.1.4.2 (Martin 2011) and poor quality sequences (scores below 20) and exact PCR replicates were removed using prinseq-lite v.0.20.4 (Schmieder and Edwards 2011). Reads were mapped to the mitochondrial genome of Genetta servalina Pucheran, 1855 (KJ624980) with Burrows-Wheeler algorithm (BWA) v.7.10 (Li and Durbin 2009) using the "bwa mem" algorithm.

The cytochrome-b (Cytb), 12S rRNA (12S), 16S rRNA (16S), control region (Dloop) and cytochrome oxidase-I (COI) genes were extracted from the whole mitochondrial genome read alignment and saved as FASTA files. A single representative for each genet species and outgroups included in the most recent phylogenetic analysis (Gaubert and Begg 2007) were downloaded from GenBank and aligned to the novel sequence using the Geneious alignment algorithm (Table 1). Phylogenies were inferred for the following datasets: 1) 5-gene dataset (Cytb, Dloop, 12S, 16S, and COI), 2) 2-gene dataset (Cytb and Dloop), and 3) 1-gene dataset (Cytb) (Table 1). The most appropriate models of sequence evolution were selected using PartionFinder v.2.1 (Lanfear et al. 2017) using the corrected Akaike information criterion (AIC), greedy search algorithm, and only using models available in MrBayes (Table 2).

Phylogenetic trees were inferred using Bayesian inference (BI) and maximum likelihood (ML). BI was performed using MrBayes v.3.2.6 (Ronquist and Huelsenbeck 2003) using four Markov-chain Monte Carlo (MCMC) runs with three heated and one cold chain. Two independent runs were conducted with 10 million generations, sampling trees and parameters every 1000 generations, and a burn-in of $25 \%$ of the sampled trees. ML analysis was performed with RAxML v. 8 (Stamatakis 2014) using GTRCAT and 1000 rapid bootstrap inferences. Both BI and ML estimates were implemented on the CIPRES science gateway (http://www.phylo.org/index.php/portal/about/). The final trees were visualized using FigTree v.1.4.3 (http:// tree.bio.ed.ac.uk/software/figtree/).

\section{Results}

\section{Specimen information}

The single specimen of an adult male Genetta abyssinica (USNM 602624) was collected by A.W. Ferguson (AWF 1220) from the following locality: Djibouti: Tadjourah Province; Forêt du Day, $0.07 \mathrm{mi} \mathrm{N}, 0.16 \mathrm{mi} \mathrm{E}$ of Airolaf, $11.7684^{\circ} \mathrm{N}$, $42.65171^{\circ} \mathrm{E}$ elevation $=1420$ a.s.l. (Garmin 62stc GPS unit, WGS84, accuracy $=3 \mathrm{~m}$ ) on 18 February 2016. This specimen represents the 19th museum voucher in the world, the first collected in over 60 years, and the first record with a precise locality for the country of Djibouti. Of the 18 other museum specimens, only 13 have detailed enough localities for obtaining unambiguous latitude and longitude coordinates, making mapping the distribution of this species challenging (Figure 1; Diaz Behrens and Van Rompaey 2002, Papeş and Gaubert 2007). The single adult male specimen's (USNM 602624) measurements including total length, tail length, hind foot length, ear length and weight were as follows: $798 \mathrm{~mm}, 374 \mathrm{~mm}, 68 \mathrm{~mm}, 47 \mathrm{~mm}$ and $720 \mathrm{~g}$ (798-374-68-47 $\equiv 720 \mathrm{~g})$. Its testes were scrotal with internal maximum length by maximum width measurements of $12 \mathrm{~mm} \times 8 \mathrm{~mm}$. These measurements fall within those provided for the other two specimens with physical measurements, i.e. 811-403-75-46 $\equiv \mathrm{X} \mathrm{g}$ (USNM 342066, adult male) and 684-361-66-43 $\equiv \mathrm{X} \mathrm{g}$ (FMNH 80818, juvenile female). As the only specimen with field weights available it is hard to compare to others, although USNM 602624 weighed less than the 1.3-2.0 kg reported in Haltenorth and Diller 


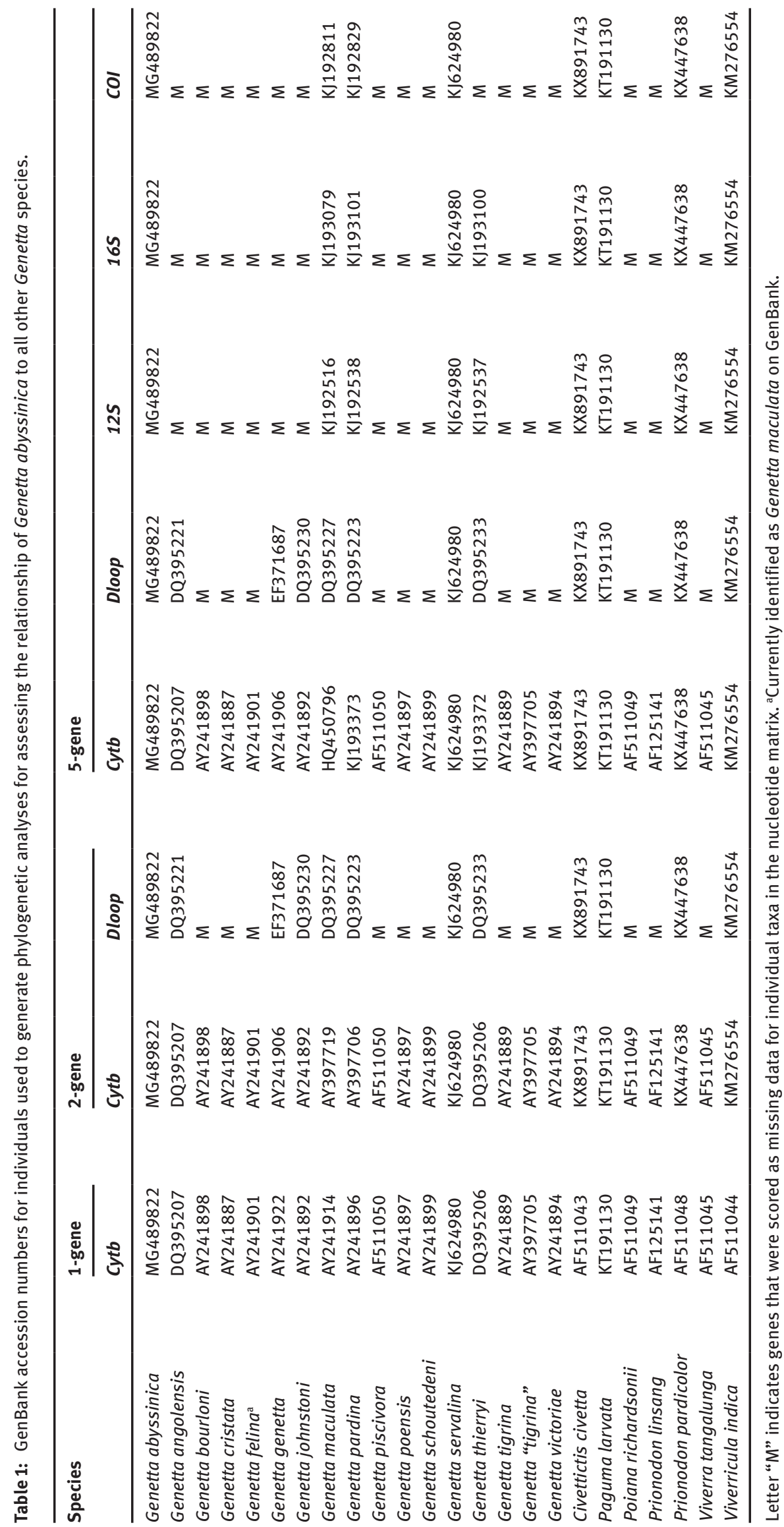


Table 2: Models of nucleotide evolution estimated from PartitionFinder version 2.1.1 (Lanfear et al. 2017) used for phylogenetic analyses of the position of Genetta abyssinica in relation to all other viverrid species.

\begin{tabular}{llrl}
\hline Subset & \multicolumn{1}{c}{ Best model } & \# Sites & \multicolumn{1}{l}{ Partition name } \\
\hline \multicolumn{2}{l}{ Cytb (1-gene) } & & \\
1 & K80+I+G & 380 & CYTB_pos1 \\
2 & HKY+I & 380 & CYTB_pos2 \\
3 & GTR+I+G & 380 & CYTB_pos3 \\
Cytb, Dloop $(2-$ gene $)$ & & \\
1 & K80+I & 380 & CYTB_pos1 \\
2 & HKY+I & 380 & CYTB_pos2 \\
3 & HKY+G & 380 & CYTB_pos3 \\
4 & GTR+G & 390 & Dloop_pos1, Dloop_pos2 \\
5 & HKY+G & 194 & Dloop_pos3 \\
Cytb, Dloop, $12 S, 16 S, C O I(5-g e n e)$ & \\
1 & HKY & 308 & 12S_pos2, 16S_pos1 \\
2 & SYM+G & 394 & COI_pos2, 16S_pos2 \\
3 & GTR & 820 & 12S_pos3, 16S_pos3, \\
& & & CYTB_pos1, 12S_pos1 \\
4 & HKY & 220 & COI_pos1 \\
5 & F81 & 219 & COI_pos3 \\
6 & GTR & 380 & CYTB_pos2 \\
7 & GTR+G & 380 & CYTB_pos3 \\
8 & GTR+G & 380 & Dloop_pos1, Dloop_pos2 \\
9 & HKY+G & 194 & Dloop_pos3 \\
\hline
\end{tabular}

(1980). External morphological characteristics including short, straight and soft pelage; dorsal spots merged in two or three dark lines (Figure 2A); central depression of the forefoot hairless (Figure 2B); the neck spots coalesced with shoulder spots forming stripes; narrow tail with 7-9 pail rings ( $\mathrm{n}=8$ for USNM 602624) indicated that morphologically the genet we collected could be identified as only G. abyssinica (Gaubert et al. 2008).

\section{Phylogenetic analysis}

The final mitochondrial genome alignment consisted of 1302 reads that successfully mapped to $97.4 \%$ of the Genetta servalina mitochondrial genome. We compared our mitochondrial genome alignment to three previously published viverrids and one prionodontid available on GenBank: G. servalina (KJ624980), Civettictis civetta (Schreber, 1776) (KX891743), Paguma larvata (C.E.H. Smith, 1827) (KT191130), and Prionodon pardicolor Hodgson, 1842 (KX447638). The Genetta abyssinica mitochondrial genome was similar in size structure and gene arrangement to other mammalian genomes; however, we were unable to determine the exact size because of several regions with low sequencing depth or poor alignment due to repetitive regions within the control region.
The G. abyssinica mitochondrial genome was 16,849 base pairs (bps) long, with $\sim 300$ bps of missing data in the following regions: $44 \mathrm{bps}$ in 165 rRNA (pos. 1489-1532), 9 bps in NADH dehydrogenase subunit 2 (ND2) (pos. 41304139), $41 \mathrm{bps}$ at the origin of replication (pos. 5182-5222), 45 bps in COX1 (pos. 6756-6800), 41 bps at the end of COX2 and beginning of the tRNA (pos. 7713-7753), 49 bps in Cytb (pos. 14,933-14,981), and $\sim 137$ bps in the control region (pos. 16,395-16,532). The control region for G. servalina contains two kinds of repetitive sequences, RS2 and RS3 (Hoelzel et al. 1994, Hassanin 2016), the first containing a 74 bps motif for which G. abyssinica shares 39 bps, and two 81 bps motifs that are shared among both species. We did not compare RS3 motifs between the species due to poor alignment in this region for G. abyssinica.

The final nucleotide alignment for the 5 -gene dataset consisted of 3305 bps for each of the 24 taxa; however, 15 taxa were missing three or four of the genes resulting

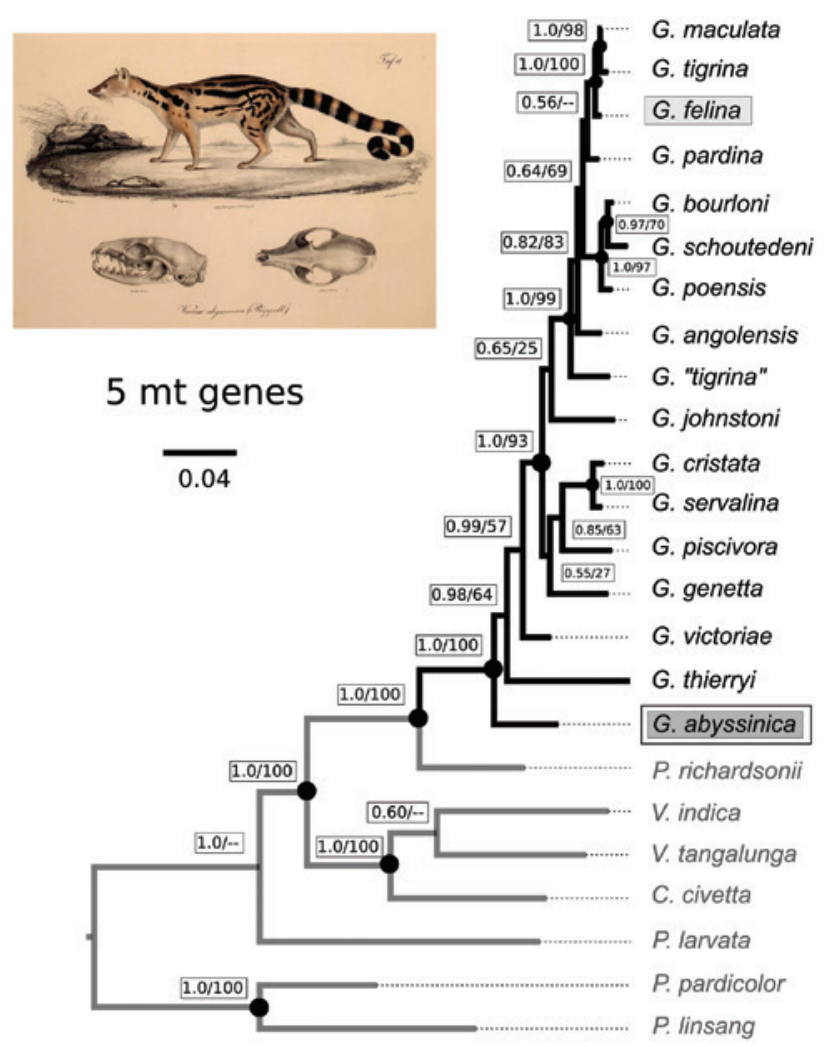

Figure 3: Phylogenetic tree for extant Genetta species and other viverrids using 3305 nucleotides of five mitochondrial genes $($ Cytb+Dloop+12S+16S+COI).

Black dots indicate well-supported nodes ( $B P P \geq 0.95, B S \geq 70$ ), nodal support values provided for nodes include Bayesian posterior probability and likelihood bootstrap. The position of the newly acquired sample of Genetta abyssinica (USNM 602624) is highlighted in dark gray. Outgroup taxa are presented in light gray text. Illustration of G. abyssinica adapted from figure 11 by artist Friedrich Carl Vogel as published in Rüppell (1835-1840). 
in a final matrix with $41 \%$ missing data. Both $\mathrm{BI}$ and ML recovered support for the monophyly of Genetta [Bayesian posterior probabilities (BPP) $=1.0$, bootstrap $(B S)=100$; Figure 3]. Interspecific relationships within the genus were poorly resolved, including the relationship of Genetta abyssinica to the other species of Genetta $(\mathrm{BPP}=0.98, \mathrm{BS}=64$; Figure 3).

Phylogenetic analyses of the 1-gene (1140 bps of Cytb, 24 taxa) and 2-gene (1140 bps of Cytb and 584 bps of Dloop, 24 taxa) datasets also recovered support for the monophyly of Genetta (BPP $=1.0, \mathrm{BS}=100$ and $\mathrm{BPP}=1.0$, $\mathrm{BS}=99$, respectively; Figure $4 \mathrm{~A}$ and $\mathrm{B})$. However, the relationship of Genetta abyssinica to other Genetta taxa was only supported with ML bootstrap analysis and not BPP ( $\mathrm{BPP}=0.57, \mathrm{BS}=70$ and $\mathrm{BPP}=0.91, \mathrm{BS}=81$, respectively).

Our phylogenetic tree appeared to match the topology reported in Gaubert et al. (2004) and Gaubert and Begg (2007) with the exception of the placement of Genetta felina (Thunberg, 1811) [AY241901, currently identified as Genetta maculata (Gray, 1830) in GenBank], which was sister to Genetta tigrina (Schreber, 1776) (AY397705) in Gaubert and Begg (2007) but sister to G. maculata AY241913 (G. maculata AY241914, G. tigrina AY241889) in our analysis (Figure 3, light gray shading). In addition, the positions of $G$. maculata
(AY241913) and G. maculata (AY241914) were reversed in our phylogeny, with G. maculata AY241913 sister to (G. maculata AY241914, G. tigrina AY241889).

\section{Discussion}

\section{Distribution of Genetta abyssinica}

Our record provides the first verifiable documentation of Genetta abyssinica for the country of Djibouti in over 60 years. The single previous specimen for Djibouti is represented by a skin collected in 1954 by E. Chèdeville deposited in the Muséum National d'Histoire Naturelle, Paris, France (MNHN 1954-323). The only additional information provided beyond collector and year collected was a locality of "Somalie Française", or French Somalia, which until 1977 was the name used for the currently recognized country of The Republic of Djibouti (Clarke 1977). However, Laurent and Laurent (2002) stated, based on Chedeville (in litt, 12 May 1992), that the specimen was most likely captured in the northern highlands, either in the Goda or in the Mabla Mountains. Laurent and Laurent
A

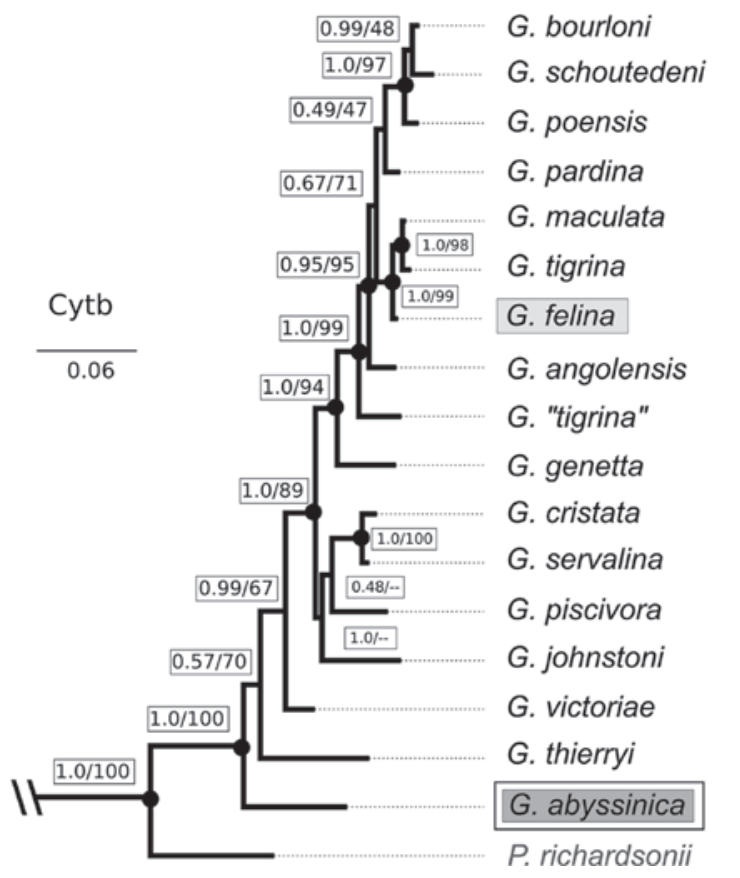

B

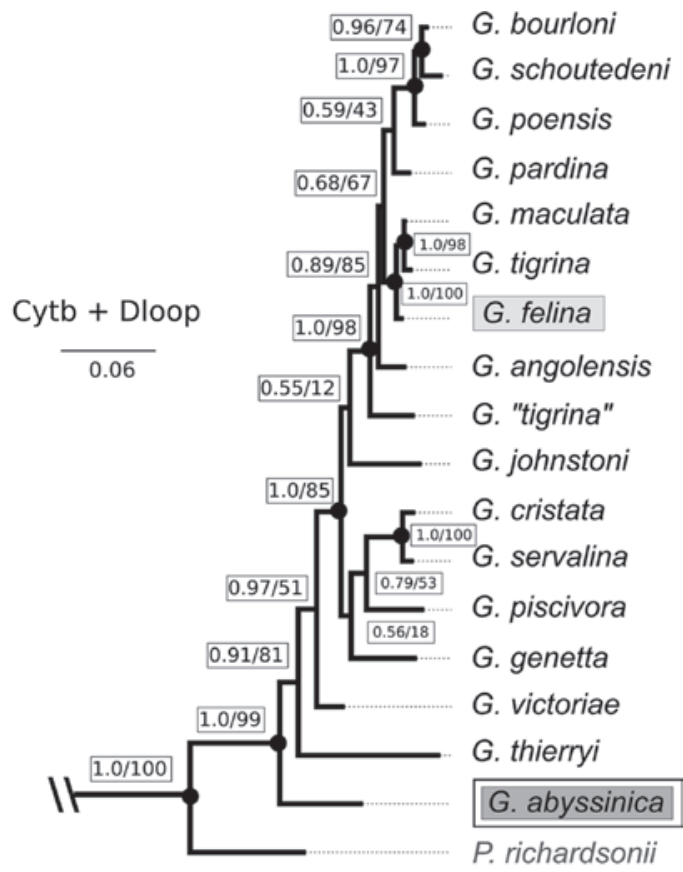

Figure 4: Phylogenetic tree for all extant Genetta species and seven outgroup taxa (not shown) generated using 1140 nucleotides of the cytochrome-b gene (A). Phylogenetic tree for Genetta species and seven outgroup taxa (not shown) using 1140 nucleotides of the cytochrome-b gene and 584 nucleotides of the Dloop gene (B). Black dots indicate well-supported nodes (BPP $\geq 0.95, B S \geq 70$ ), nodal support values provided for nodes include Bayesian posterior probability and likelihood bootstrap. The position of the newly acquired sample of Genetta abyssinica (USNM 602624) is highlighted in dark gray. The conflicting placement of G. felina (AY241901) is highlighted in light gray. 
(2002) go on to state that G. abyssinica is present in the country, although probably rare to very rare. Despite this assertion, G. abyssinica does not have any special protection and is currently recognized by the International Union for Conservation of Nature (IUCN) as Data Deficient (Gaubert et al. 2016), limiting our ability to draw any meaningful conclusions about its conservation status in Djibouti. Künzel et al. (2000) questioned the presence of this genet in Djibouti. Interestingly, it appears that despite being considered a non-forest species of genet, current records of G. abyssinica from Djibouti are restricted to the high elevation montane juniper forests of the Goda and the Mabla Mountains, including the Forêt du Day. Of course, additional sampling of lowland habitats contiguous with those that have existing records of $G$. abyssinica such as the Ethiopian xeric grasslands and shrublands (Olson et al. 2001) along coastal Somalia (BMNH 34.9.14.20; Figure 1) are vital to understanding the distribution of this species in Djibouti. Although not exhaustive, 24 live-trap nights spent in this habitat in and around Camp Lemmonier $\left(11^{\circ} 32^{\prime} 30^{\prime \prime} \mathrm{N}, 43^{\circ} 10^{\prime} 00^{\prime \prime} \mathrm{E}\right.$; $5 \mathrm{~m}$ a.s.l.) resulted in the capture of a single white-tailed mongoose but no genets, although animal control agents reported capturing unknown genet species on the base. Additional carnivores observed in this area at the time of trapping included Ruppell's fox Vulpes rueppelli (Schinz, 1825) and domestic cats.

The 20 records of Genetta abyssinica with localities precise enough to allow for coordinate assignment (see Papeş and Gaubert 2007 and Diaz Behrens and Van Rompaey 2002 for tables of records) are distributed across six major ecoregions: East Sudanian savanna $(n=1)$; Ethiopian montane grasslands and woodlands (5); Ethiopian montane moorlands (9); Ethiopian xeric grasslands and shrublands (2, including our specimen); Sahelian Acacia Savanna (2); Somali Acacia-Commiphora Bushlands and thickets (1). Although identifying suitable ecoregions based on these records are confounded by imprecise locality information and the coarse resolution of the ecoregions themselves (Olson et al. 2001), such information provides a starting point for continued surveys of this species. Only through additional, verifiable records in the form of vouchers, with precise locality data will we be able to truly delimit the ecologic and geographic limits of G. abyssinica across the Horn of Africa.

\section{Phylogenetic position of Genetta abyssinica}

Our phylogenetic results provided the first exhaustive molecular phylogeny for all 14 currently recognized species of Genetta (Gaubert et al. 2004, Gaubert 2013) and indicate that Genetta abyssinica may be the sister taxa to all other genets (Figures 3 and 4). Although statistical support for this relationship between G. abyssinica and all other Genetta varied across the different analyses, if this relationship holds true it would differ from that proposed by Gaubert et al. (2002) based on morphological characters alone. Using these morphological characters, Gaubert et al. (2004) hypothesized that G. abyssinica would be sister to Genetta thierryi, and a clade sister to all other Genetta (see Figure 3 in Gaubert et al. 2004). The potential lack of phylogenetic support for a sister relationship between G. abyssinica and G. thierryi would be surprising given the fact that they share several morphological synapomorphies (Gaubert et al. 2002). However, the proximity of G. abyssinica to the oyans (Poiana) and G. thierryi is not surprising given the shared plesiomorphic characters between these species (Gaubert et al. 2002). The overall lack of consistent statistical support for the placement of G. abyssinica in the Genetta phylogeny as well as limited support for additional internal nodes indicates that additional data, taxa and molecular markers are still necessary to resolve the evolutionary relationships among extant genets. Our results, although not consistently supported statistically, provide a potential alternative hypothesis for future testing, specifically that $G$. abyssinica is sister to all other species of genets, including $G$. thierryi.

The phylogenetic placement of Genetta abyssinica has consequences for interpreting the biogeographic history of this complex and diverse group of African small carnivores. In particular, a lack of phylogenetic support for the sister relationship to Genetta thierryi implies that there would be two independent "exits" of genets into African open habitats from the rain-forest adapted ancestor (Gaubert et al. 2004). However, in light of recent records of G. abyssinica in forested habitats (Diaz Behrens and Van Rompaey 2002, this article), perhaps assuming it is truly an "open habitat" species is a bit premature; without additional records with good locality information, we are left with weak inference into this species ecology and habitat requirements. Nevertheless, G. abyssinica is clearly not a rain forest species and therefore does represent a divergence form the estimated ancestral state of Genetta (Gaubert et al. 2004). Although a number of studies address the phylogenetic relationships of Genetta, there still appears to be a need for additional systematic studies of this group using nuclear markers or next-generation approaches.

\section{Ecology of Genetta abyssinica and implications for conservation}

This article highlights the need for continued surveys and collecting of vouchered specimens of small carnivores 
such as Genetta abyssinica in order to better understand both their evolutionary history and ecological requirements. The need for vouchers for these morphologically complex species is further highlighted by the recent report of a road-killed G. abyssinica from Ethiopia (Balakrishnan and Afework 2008), which subsequent inspections confirmed was actually Genetta genetta (Linnaeus, 1758) (Gaubert et al. 2009). Without the availability of a voucher for subsequent re-identification, this record could have been perpetuated as a new occurrence for $G$. abyssinica in Ethiopia, potentially confounding the ability to determine the species range and habitat requirements. Collection of a single individual allowed us to increase our understanding of this species from an evolutionary, ecological and biological standpoint, providing materials for use in future studies including pathogen exploration and ecomorphological analysis of postcranial materials. This record provides information on a misunderstood and little studied species of mammal from an area ecologically important to the critically endangered Djibouti Francolin, bolstering the need to protect this fragile yet important wooded ecosystem. Additional surveys of both montane forested regions (e.g. the Mabla Mountains) and lowland desert scrub (e.g. south-east Djibouti) should provide further information on the geographic distribution of this species in Djibouti, facilitating appropriate management and conservation of G. abyssinica.

Acknowledgment: The biodiversity surveys of Camp Lemonnier and the Forêt du Day were supported by the Smithsonian Institution (SI) Global Genome Initiative (GGI) and the US Navy Natural Resources Program by grants procured by Carla Dove. Funding and technical support for laboratory work including DNA sequencing was provided by the Smithsonian Institution's DNA Barcode Network and the Center for Conservation Genomics, National Zoological Park. We thank Carla Dove and Suzanne Peurach for the opportunity to participate in these expeditions. We also thank Carla Dove, James Whatton, Brian Schmidt, and Jeremy Jacobs (National Museum of Natural History); Steve Gotte (U.S. Geological Survey); Matt Klope (retired, U.S. Navy); Abdourahman Ismael and Yahya Moumine (University of Djibouti); and Ms. Adwa Ali (Center for Education and Research Department, Djibouti) for assistance and comradery in the field. Laura Muhs (Camp Lemonnier Environmental Program Director, U.S. Navy) provided extensive logistical support during the expedition. Calvin Lotiaco and Jose Flores, KBR Vector Control contractors provided information on fauna of Camp Lemonnier. Permits were granted via Mr. Houssein Rirache Roble, Director of Environment and Sustainable Development Ministry of Housing, Urban Planning and Environment, Djibouti and the SI Institutional Animal Care and Use Committee (IACUC 2014-11). The expeditions to Camp Lemonnier were coordinated via the U.S. Embassy in Djibouti and we thank the staff there for assistance.

\section{References}

Balakrishnan, M. and B. Afework. 2008. A road kill of the Ethiopian genet Genetta abyssinica along the Addis Ababa-Dira Dewa highway, Ethiopia. Small Carnivore Conserv. 39: 37-38.

Clarke, W.S. 1977. The Republic of Djibouti - an introduction to Africa's newest state and a review of related literature and sources. Curr. Bibl. Afr. Aff. 10: 3-31.

Crawford-Cabral, J. 1981. The classification of the genets (Carnivora, Viverridae, genus Genetta). Boletim da Sociedade Portuguesa de Ciências Naturais. 20: 97-114.

Diaz Behrens, G. and H. Van Rompaey. 2002. The Ethiopian genet, Genetta abyssinica (Rüpell 1836) (Carnivora, Viverridae): ecology and phenotypic aspects. Small Carnivore Conserv. 27: 23-28.

Fisher, Z.S., S. Cartwright, C. Bealey, H.A. Rayaleh, P. McGowan and E.J. Milner-Gulland. 2009. The Djibouti francolin and juniper forest in Djibouti: the need for both ecosystem and speciesspecific conservation. Oryx 43: 542-551.

Gaubert, P. 2013. Genetta abyssinica Ethiopian genet. In: (J. Kingdon and M. Hoffman, eds.) Mammals of Africa: Volume V: Carnivores, pangolins, equids, and rhinoceroses. Bloomsbury Publishing, London. pp. 216-218.

Gaubert, P. and C.M. Begg. 2007. Re-assessed molecular phylogeny and evolutionary scenario within genets (Carnivora, Viverridae, Genettinae). Mol. Phylogent. Evol. 44: 920-927.

Gaubert, P., G. Veron and M. Tranier. 2002. Genets and 'genet-like' taxa (Carnivora, Viverrinae): phylogenetic analysis, systematics and biogeographic implications. Zool. J. Linn. Soc. 134: 317-334.

Gaubert, P., C.A. Fernandes, M.W. Bruford and G. Veron. 2004. Genets (Carnivora, Viverridae) in Africa: an evolutionary synthesis based on cytochrome b sequences and morphological characters. Biol. J. Linn. Soc. 81: 589-610.

Gaubert, P., A. Chalubert and G. Dubus. 2008. An interactive identification key for genets and oyans (Carnivora, Viverridae, Genettinae, Genetta spp. and Poiana spp.) using Xper². Zootaxa 1717: 39-50.

Gaubert, P., M. Balakrishnan and A. Bekele. 2009. Corrigendum: "A road kill of the Ethiopian Genet Genetta abyssinica along the Addis Ababa-Dira Dewa Highway, Ethiopia” by Mundanthra Balakrishnan and Afework Bekele (2008, Small Carnivore Conserv. 39: 37-38). Small Carnivore Conserv. 40: 40.

Gaubert, P., J.W. Duckworth and E. Do Linh San. 2016. Genetta abyssinica. The IUCN Red List of Threatened Species 2016: e.T8994A45198149.

Haltenorth, T. and H. Diller. 1980. A field guide to the mammals of Africa including Madagascar. Collins, London. pp. 400.

Hassanin, A. 2016. The complete mitochondrial genome of the Servaline Genet, Genetta servalina, the first representative from the family Viverridae (Mammalia, Carnivora). Mitochondrial DNA Part A 27: 906-907.

Hoelzel, A.R., J.V. Lopez, G.A. Dover and S.J. O’Brien. 1994. Rapid evolution of a heteroplasmic repetitive sequence in the 
mitochondrial DNA control region of carnivores. J. Mol. Evol. 39: 191-199.

Künzel, T., H.A. Rayaleh and S. Künzel. 2000. Status assessment survey on wildlife in Djibouti. Final Report, Zoological Society for the Conservation of Species and Populations (Z.S.C.S.P.) and Office National du Tourisme et de l'Artisanat (O.N.T.A.). pp. 78.

Lanfear, R., P.B. Frandsen, A.M. Wright, T. Senfeld and B. Calcott. 2017. PartitionFinder 2: new methods for selecting partitioned models of evolution for molecular and morphological phylogenetic analyses. Mol. Biol. Evol. 34: 772-773.

Laurent, A. and D. Laurent. 2002. Djibouti; Les Mammifères d'hier à aujourd'hui pour demain. Editions BEIRA. CFP. Toulouse. France. pp. 240.

Li, H. and R. Durbin. 2009. Fast and accurate short read alignment with Burrows-Wheeler transform. Bioinformatics 25: 1754-1760.

Martin, M. 2011. Cutadapt removes adapter sequences from highthroughput sequencing reads. EMBnet.journal 17: 10-12.

Olson, D.M., E. Dinerstein, E.D. Wikramanayake, N.D. Burgess, G.V.N. Powell, E.C. Underwood, J.A. D’Amico, I. Itoua, H.E. Strand, J.C. Morrison, C.J. Loucks, T.F. Allnutt, T.H. Ricketts, Y. Kura, J.F. Lamoreux, W.W. Wettengel, P. Hedao and K.R. Kassem. 2001. Terrestrial ecoregions of the world: a new map of life on Earth. Bioscience 51: 933-938.

Papeş, M. and P. Gaubert. 2007. Modelling ecological niches from low numbers of occurrences: assessment of the conservation status of poorly known viverrids (Mammalia, Carnivora) across two continents. Divers. Distrib. 13: 890-902.

Rohland, N. and D. Reich. 2012. Cost-effective, high-throughput DNA sequencing libraries for multiplexed target capture. Genome Res. 22: 939-946.

Ronquist, F. and J.P. Huelsenbeck. 2003. MrBayes 3: Bayesian phylogenetic inference under mixed models. Bioinformatics 19: 1572-1574.

Rüppell, E. 1835-1840. Neue Wirbelthiere zu der Fauna von Abyssinien gehörig. Frankfurt am Main.

Sasaki, T., M. Nikaido, H. Hamilton, M. Goto, H. Kato, N. Kanda, L.A. Pastene, Y. Cao, R.E. Fordyce and M. Hasegawa. 2005. Mitochondrial phylogenetics and evolution of mysticete whales. Systematic Biol. 54: 77-90.

Schmieder, R. and R. Edwards. 2011. Quality control and preprocessing of metagenomic datasets. Bioinformatics 27: 863-864.

Sikes, R.S. and Animal Care and Use Committee of the American Society of Mammalogists. 2016. 2016 Guidelines of the American Society of Mammalogists for the use of wild mammals in research and education. J. Mammal. 97: 663-688.

Stamatakis, A. 2014. RAxML Version 8: A tool for phylogenetic analysis and post-analysis of large phylogenies. Bioinformatics 30: 1312-1313.

Yalden, D., M. Largen, D. Kock and J. Hillman. 1996. Catalogue of the mammals of Ethiopia and Eritrea. 7. Revised checklist, zoogeography and conservation. Trop. Zool. 9: 73-164. 